\title{
LETTER FROM THE GUEST EDITOR
}

Embodying aspects of science, art, and technology, the field of cartography has a corpus of knowledge which is extensive: it interacts and overlaps with other disciplines to an enormous degree; and it is utilised and delivered in a wide range of contexts, from state-directed mass production agencies to personal mapmakers disseminating experimental visualisations over the web; and from knowledge engineers conceptualising database design to social historians interpreting apocryphal sketch maps traced on the Rhodian shore.

This special issue of Cartographic Perspectives, addressing issues related to "Education in Cartography," reflects the breadth of study embodied by cartography. The scope of cartographic data handling is immense, and it is no surprise that large numbers of school, college, and mature students have a natural interest in, and commitment to, the subject of cartography. The way in which we teach and inform them of the nature of our discipline is critical: from the beginning of their educational experiences, such scholars can be prudently introduced to a vast range of description, interpretation, and analysis of the elemental tasks of a dynamic and fundamental discipline. The nurturing of societies of knowledgeable and committed citizens through means of education forms an unwritten contract which binds generations together: the rightful expectation of the young is that they will be educated by their elders, to transfer learning, experiences, and skills, along with the intelligence to recognise how they can improve society by enhancing previous knowledge and gaining wisdom.

The subject matter of cartographic education is a three thousand year-old body of accumulated wisdom, which is the core of "what" is to be taught. There is, therefore, a significant amount of material which forms that subject matter. Some is addressed because of curiosity; some addresses the accepted truisms of our discipline; some demonstrates the integral links of cartography to other human endeavours; some contributes to the status of cartographers as "experts" in their craft. Each aspect forms part of a "Body of Knowledge," defining the content of our educational curricula. The dynamic nature of contemporary cartographic activity and its potential adaptation to future changes means there is an obligation for cartographic educators to regularly, in the light of advances in the discipline, revise the syllabus they teach; to take advice from industrial advisory panels, professional organisations, and institutional/governmental reports; to maintain contact with alumni who are succeeding in the cartographic profession; and to increase the effectiveness of research-led teaching. In short, the varying experiences of those engaged in the nation's classrooms in delivering education in cartography should be reported, disseminated, and considered. A new regular section within Cartographic Perspectives, entitled "Views on Cartographic Education" and edited by Fritz 
Kessler, will present such experiences, and all are encouraged to submit educational items to Cartographic Perspectives for inclusion. Fritz introduces this new section later in this issue.

The new section will join other regular $C P$ columns and, to preserve continuity, we have included some of these columns in this special issue, where appropriate. In "Cartographic Collections" (which focuses on map curatorship, documentation, and conservation), an account of the outreach work of the Boston Public Library is presented, with an emphasis on educating the public on the importance and value of an accessible municipal map collection. In the "Practical Cartographer's Corner" (presenting tips and experiences from those engaged in map design, creation, and production) the educational theme is maintained with an interesting account of production work being done by students in the labs of the University of Nebraska at Omaha. Finally, in "Visual Fields" (which addresses "cartographic aesthetics and design, featuring examples of inspirational, beautiful, and intriguing work"), David Rumsey presents a fascinating artefact of early $19^{\text {th }}$ century school-level education using maps, in the form of an atlas of the United States for blind children.

A number of other aspects of education are exemplified in the main reviewed papers of this special issue of Cartographic Perspectives. Pedagogy (the practice of teaching) is addressed in each. The online theme is considered further by Anthony Robinson, who has been at the forefront of promoting the most substantial increase in numbers of students of cartography in recent years, through his leadership of a massive open online course (MOOC) developed by Penn State University and commercial partner Coursera. Anthony's paper addresses, in particular, scalability issues in assessment of students registered for a distance-learning MOOC. In the context of an overview of how MOOCs developed, several detailed aspects of evaluating student work are considered. Peer grading, the role of visual analysis, iterative design, progressive improvement, and detection of plagiarism in submitted material are each explored. A dynamic discipline such as cartography needs dynamic methods of educational discourse: MOOCs show one example of how contemporary technology can be used to renew cartographic education, and this paper probes important topics related to their implementation.

The outcomes of education are considered in the other main paper in this issue, in which Jeff Howarth reflects on spatial thinking and the pedagogy of GIS. Undertaking some practical testing of students on geography and GIS degree programmes, Jeff has been able to demonstrate the value of spatial thinking in education in many disciplines, how to enhance natural spatial thinking abilities, and how to "teach the teachers" to value spatial thinking in their syllabus development. The importance of Jeff's experiences to the development of cartographic education is in integrating conceptual issues in education, such as cognitive load theory and studies of expert knowledge, with the classroom activities involved in spatial learning.

The generic topics (in bold, above) covered in this special issue of CP are central to the agenda of the International Cartographic Association's newly re-elected (2015-2019) Commission on Education and Training. One of its long-standing Terms of Reference is to monitor the provision of cartographic education around the world: the Commission has noted with concern the decline in cartographic education provision in some countries such as the United Kingdom, the Netherlands, and Germany, but also welcomes the burgeoning of cartographic education in other nations including Spain, Turkey, China, and Brazil. On the strength of its dynamic practitioners (both within the academy and through collaborative 
commercial/governmental links), their innovation in publication and outreach, the flexibility of curriculum development informed by comprehensive Body of Knowledge and competency model documents, and the vitality of research activity, the United States also falls into the latter category. The initiative for this special issue of Cartographic Perspectives came from a realisation that the incisive discussions, debates, and presentations on the topic of education in cartography at the April 2015 meeting of the Association of American Geographers deserved a fuller exploration and broader arena in which to be aired. Along with the regular, stimulating meetings of American cartographers in other forums, through organisations such as NACIS, there is admirable opportunity for cartographic educators in the USA to be innovative, effective, and pro-active in their approach. It is to be hoped that the experiences of American cartographic educators, involved in the range of topics mentioned above, from Body of Knowledge to public outreach, and from web mapping in the classroom to developing a cartographic "mind-set," can continue to be described and disseminated in a way which helps the international community. This issue of Cartographic Perspectives is a major step in that direction.

David Fairbairn

Guest Editor 